\title{
Development and behaviour of 5-year-old very low birthweight infants
}

\author{
Liisi Rautava - Sture Andersson - Mika Gissler • Mikko Hallman • \\ Unto Häkkinen · Emmi Korvenranta · Heikki Korvenranta · Jaana Leipälä • \\ Outi Tammela $\cdot$ Liisa Lehtonen
}

Received: 19 November 2009/ Accepted: 3 March 2010/Published online: 23 March 2010

(C) Springer-Verlag 2010

\begin{abstract}
The place and time of birth influence the mortality of premature infants. We studied the effect of prematurity, time of birth, birth hospital level and district on the development and behaviour in a national cohort of 5-year-old Finnish very low birthweight infants (VLBWI). All surviving VLBWI (gestational age $<32$ weeks or birthweight $\leq 1,500 \mathrm{~g}$ ) born in 2001-2002 in level II or III hospitals in Finland and full-term controls were included. The parents of 588 (64\%) VLBWI and 176 (46\%) controls returned the Five to Fifteen questionnaire (FTF) on the development and behaviour of their 5-year-old children. The questionnaire scores were linked to data from the National Medical Birth Register, the Hospital Discharge Register, the Register of Congenital Malformations and the Cause of Death Register. VLBWI had lower developmental
\end{abstract}

For PERFECT Preterm Infant Study Group.

L. Rautava $(\varangle) \cdot$ E. Korvenranta $\cdot$ L. Lehtonen

Department of Pediatrics, Turku University Hospital,

Kiinamyllynkatu 4-8, 20520 Turku, Finland

e-mail: liisi.rautava@utu.fi

S. Andersson

Hospital for Children and Adolescents, Helsinki, Finland

M. Gissler · U. Häkkinen · J. Leipälä

National Institute for Health and Welfare, Helsinki, Finland

M. Hallman

Department of Pediatrics, Oulu University Hospital,

Oulu, Finland

H. Korvenranta

Turku University Hospital, Turku, Finland

O. Tammela

Department of Pediatrics, Tampere University Hospital,

Tampere, Finland and behavioural scores compared to the controls in all FTF domains. In VLBWI, the scores were less optimal, the lower the gestational age was. The time of birth, birth hospital level and district were not associated with the developmental and behavioural scores in VLBWI. In conclusion, short duration of pregnancy adversely influences development and behaviour in VLBWI. Despite differences previously demonstrated in mortality related to time and place of birth, there were no differences in developmental and behavioural scores in VLBWI according to the time of birth, birth hospital level or district. Thus, the survival advantage in level III hospitals seems not to be gained at the expense of behavioural or developmental problems.

Keywords Development - Behaviour - Five to Fifteen · Follow-up $\cdot$ Preterm infant $\cdot$ Regionalisation

$\begin{array}{ll}\text { Abbreviations } & \\ \text { FTF } & \text { Five to Fifteen questionnaire } \\ \text { GA } & \text { Gestational age } \\ \text { RR } & \text { Rate ratio } \\ \text { SGA, AGA and LGA } & \begin{array}{l}\text { Small, appropriate and large birth- } \\ \text { weight for gestational age }\end{array} \\ \text { VLBWI } & \text { Very low birthweight infants }\end{array}$

\section{Introduction}

The concern over long-term outcomes and the lowering limits of viability [1-3] of very premature infants set special challenges to the organisation of care of this patient group. A high birth hospital level has been associated with lower mortality rates of very premature infants in several 
countries [4-6]. In our own data, birth at level II hospitals increased the adjusted risk of mortality for VLBWI more than twofold compared to birth at level III hospitals [5]. A very premature birth in the daytime [7] has also been linked to lower mortality rates of very premature infants in California, and a trend towards lower mortality of VLBWI born during office hours has been seen in comparison to those born outside office hours in Finland [5]. In Finland, differences between the university hospital district of birth have been seen in the length of initial hospital stay of VLBWI [8] and in mortality of extremely low birthweight infants (ELBWI) [9]. Tommiska et al. [9] reported differences between hospital districts in short-term morbidities of ELBWI born in 1996-1997, but these differences were not further specified and were no longer found in those ELBWI born in 1999-2000.

High incidence of developmental and behavioural problems has been reported in earlier literature in children born preterm. At 5 years of age, only $39 \%$ of children born before 30 weeks [10], and 59\% of children born below 32 weeks of gestation [11] had normal developmental outcomes. In Finnish children born with a birthweight less than $1,000 \mathrm{~g}$, the neurological outcome was considered normal in $57 \%$ [12]. The risk of hyperactive behaviour is increased in 5-year-old children born extremely prematurely [13]. Preterm children also show more externalising and internalising behaviour, and have a twofold risk of attention-deficit and hyperactivity disorder compared to full-term controls, and mean cognitive scores are directly proportional to birthweight and gestational age [14].

A study on the long-term effects of birth hospital level in VLBWI [15] found no differences in neurosensory disabilities, or the behavioural and educational outcomes at 7-8 years of age. However, visual outcome varied according to birth hospital level [15]. In our data, the time of birth or the birth hospital level were not associated with the quality of life at age 5 or the quality-adjusted life-years [16], the use of health care services, or with subsequent prematurity-related morbidity [17]. Although it is essential to know how the organisation of the care during the perinatal period and early infancy affect the long-term outcome of children born very preterm, there are, to our knowledge, no studies on the effects of the time of birth or birth hospital region on the development or behaviour of this patient group. Therefore, the first aim of this study was to evaluate the development and behaviour of 5-year-old VLBWI in Finland compared with full-term controls. The second aim was to elucidate the effect of a birth outside office hours, and the birth hospital level and the university hospital district as predictors of developmental and behavioural outcome in a national cohort of VLBWI. Our hypotheses were that prematurity itself and a premature birth in a level II hospital or outside office hours are associated with increased developmental and behavioural problems. We also hypothesised that regional differences in mortality are reflected in later outcome, i.e. that VLBWI born in districts with lower mortality rate also have less developmental and behavioural problems.

\section{Methods}

The study population

This study included all surviving VLBWI (gestational age, GA $<32$ weeks or birthweight $\leq 1,500 \mathrm{~g}$ ) born in Finland in 2001-2002. The healthy full-term (GA 38-42 weeks) infants matched for sex and born in the same delivery hospital next in order after every third VLBWI were chosen for the control group. "Healthy" was defined as an infant with no hospital admission during the first 7 days of life. In Finland, university hospitals have a paediatrician or a neonatologist at the hospital $24 \mathrm{~h}$ a day and a neonatologist on call as a backup. The central hospitals have 24-h emergency service, but they are not required to have a paediatrician or a neonatologist at the hospital outside office hours. In 2001-2002, each university hospital had at least 43 VLBWI deliveries per year, whereas each central hospital had less than 27 VLBWI deliveries per year. When categorised as proposed by the American Academy of Pediatrics Committee on Fetus and Newborn [18], all five university hospitals in Finland are at least level IIIB hospitals and the 14 central hospitals where the study VLBWI were delivered are at least level IIB hospitals. These hospitals are referred to in the following text as level III and level II hospitals, respectively.

The exclusion criteria were (1) an incomplete personal identification number in the National Medical Birth Register preventing data linkage ( $n=6$ in VLBWI and $n=0$ in controls); (2) a major disparity between GA and birthweight or missing data on either one of these variables suggesting entering error in the database $(n=29)$; (3) a birth at a level I hospital or at a hospital with less than three deliveries of live-born VLBWI within the study period $(n=4)$; and (4) a lethal congenital malformation $(n=19)$. Lethal congenital malformations were defined as trisomy 13 or 18, triploidy, severe cardiac defects (acardia, univentricular heart, transposition of great arteries and interrupted aorta), severe cerebral malformations (anencephaly and holoprosencephaly) and other lethal conditions. The size of the study population was 924 VLBWI and 381 controls after the exclusions.

The questionnaires were not sent to families who lived abroad at the time the questionnaires were mailed, whose address was missing from the Central Population Register, or who had denied the register keepers to release their address ( $n=23$ VLBWI and $n=13$ controls). 


\section{Data construction}

Questionnaires on the development and behaviour of the children were sent to their home address $0.5-1.5$ months prior to the fifth birthday. Reminders were mailed 1.5 and 2.5 months later, if necessary. The questionnaire included three parts, which were filled in by (1) one or both parents, (2) the mother and (3) the father separately. The parents' questionnaire included the Five to Fifteen questionnaire (FTF), which is a validated instrument including 181 questions on development and behaviour applicable to children aged 5-15 [19-22]. The parents were asked to compare their child to children of the same age and to circle one of the three alternatives that best described their child: $0=$ does not describe, $1=$ describes to some extent, and $2=$ describes well. After consulting one of the copyright holders (Dr. M. Korkman), we removed questions 16, 48-51, 63-64 and 93-105, which are not fully applicable to children prior to school age. The removed items included sub-domains on time concepts, reading/ writing and mathematics. The individual items of the FTF have been listed in a previous publication [20].

The data from the questionnaires were linked to the Finnish National Medical Birth Register, the Hospital Discharge Register, the Register of Congenital Malformations and the Cause of Death Register for background information.

\section{Statistical analyses}

The FTF developmental and behavioural scores of VLBWI were compared to those of the controls. The relationships of the scores of the VLBWI and the birth hospital level, university hospital district and the time of birth during or outside office hours was also assessed. Births during public holidays, on weekends, or weekdays from 4:01 PM to 7:59 AM were considered births "outside office hours". $60 \%$ of the deliveries of VLBWI occurred outside office hours. Comparisons including both VLBWI and controls were adjusted for sex, the mother's and the father's years of education and current employment status (1 employed, 2 unemployed, or 3 at home taking care of a family member), and family structure ( 1 two biological parents, 2 single parent or joint custody, 3 a biological parent and a stepparent, or 4 foster care or adoption family). These adjustments were chosen because sex and parental education used as a measure of socioeconomic status have been shown to be associated with FTF scores [19, 20]. The same adjustments were used in the comparisons within the VLBWI. In addition, comparisons within the VLBWI were adjusted for intrauterine growth, multiple births (number of children), gestational age, birthweight and non-lethal malformations. We categorised intrauterine growth as small (SGA), appropriate (AGA), or large (LGA) birthweight for GA, which were defined as birthweight $<-2 \mathrm{SD}$, between $-2 \mathrm{SD}$ and $2 \mathrm{SD}$ and $>2 \mathrm{SD}$, respectively, according to sex-specific reference values from the Finnish population.

The statistical analyses of the FTF scores were performed using generalised linear models. The response distribution of the sums of the FTF scores was negative binomial, and the link function was log. In the analysis of FTF scores, the logarithm of the number of answered questions was used as the offset variable. Results of these comparisons are given as rate ratios (RR) with $95 \%$ confidence intervals (CI) or as $p$ values. The results were also considered in relation to the normative values previously obtained from a sample of 5.0-5.5-year-old Finnish children [23]. Children whose domain score exceeded the 98th percentile limit of the normative children were regarded as having considerable difficulties in the particular domain area.

The effect of GA on the eight main FTF domains was studied separately in VLBWI. The covariates included in the model were the same variables that were used in the adjustments for VLBWI. However, birthweight was not included in the model because of multicollinearity with GA and the categorised intrauterine growth.

All statistical analyses were performed using SAS for Windows, version 9.1.3 (SAS Institute, Cary, NC, USA). $p$ value $<0.05$ was considered statistically significant.

\section{Ethics}

The parents gave their written informed consent to participating in the study. The study protocol was approved by the Ethics Committee of the National Research and Development Centre for Welfare and Health, and the study has been performed in accordance with the ethical standards laid down in the 1964 Declaration of Helsinki. The register keeping organisations gave their permission to use their register data in this study.

\section{Results}

The mortality up to the age of 5 years was $12 \%$ in the VLBWI and $0 \%$ in the controls. The FTF was returned by $588(64 \%)$ parents of the VLBWI and $176(46 \%)$ parents of the controls. The percentages of parents of VLBWI that returned the FTF were $66 \%$ for those born in level III hospitals, $60 \%$ for those born in level II hospitals, $65 \%$ for those born during office hours and $64 \%$ for those born outside office hours. The background characteristics of the study participants are shown in Table 1 . According to the drop-out analysis reported elsewhere [16], the mothers of 
Table 1 Background data of the VLBWI and the controls whose parents returned the Five to Fifteen questionnaire

\begin{tabular}{|c|c|c|}
\hline & VLBWI $(n=588)$ & Controls $(n=176)$ \\
\hline \multicolumn{3}{|l|}{ Variables from the National Medical Birth Register Data } \\
\hline Gestational age, weeks and days, mean (SD) & $294 / 7(23 / 7)$ & $396 / 7(10 / 7)$ \\
\hline Birthweight (g) [mean (SD)] & $1,249(382)$ & $3,570(436)$ \\
\hline Female sex $(\%)$ & 43 & 41 \\
\hline Maternal years of education [mean (SD)] & $14.6(2.8)$ & $15.5(2.8)$ \\
\hline Paternal years of education [mean (SD)] & $13.7(3.1)$ & $14.7(3.0)$ \\
\hline Mother employed (\%) & 74 & 78 \\
\hline Mother unemployed (\%) & 5 & 0 \\
\hline Mother at home taking care of a family member (\%) & 22 & 22 \\
\hline Father employed (\%) & 95 & 93 \\
\hline Father unemployed (\%) & 5 & 4 \\
\hline Father at home taking care of a family member $(\%)$ & 1 & 2 \\
\hline Maternal age at delivery [mean (SD)] & $30.7(5.8)$ & $30.0(5.6)$ \\
\hline Previous pregnancies ending with foetal death [mean (SD)] & $0.6(1.0)$ & $0.4(0.74)$ \\
\hline Previous deliveries [mean (SD)] & $0.8(1.4)$ & $0.9(1.1)$ \\
\hline Mothers smoking during pregnancy $(\%)$ & 14 & 9 \\
\hline Number of antenatal visits [mean (SD)] & $13.0(9.7)$ & $17.1(5.2)$ \\
\hline \multicolumn{3}{|l|}{ Variables from the 5-year follow-up } \\
\hline Two biological parents $(\%)$ & 86 & 84 \\
\hline Single parent or joint custody $(\%)$ & 12 & 14 \\
\hline One biological parent and a step-parent (\%) & 2 & 2 \\
\hline Foster care or adoption $(\%)$ & 1 & 0 \\
\hline Number of visits at special health care maternity ward [mean (SD)] & $3.1(3.0)$ & $2.9(3.1)$ \\
\hline Multiple births (number of children) [mean (SD)] & $1.3(0.5)$ & $1.0(0.1)$ \\
\hline Number of emergency visits at special health care from birth to 5 years [mean (SD)] & $2.4(3.0)$ & $0.8(1.4)$ \\
\hline Number of other visits at special health care from birth to 5 years [mean (SD)] & $20.8(19.9)$ & $2.6(6.6)$ \\
\hline Hospitalised or institutionalised from birth to 5 years (days) [mean (SD)] & $68.4(39.5)$ & $1.0(2.7)$ \\
\hline
\end{tabular}

the non-responder group had more previous foetal deaths, more multiple births and smoked more often during the pregnancy than the mothers of the responder group. Parents to VLBWI boys responded more often than parents to the girls. However, the birthweight or the GA did not differ between the groups, and there were no significant differences in the number of emergency or non-emergency visits to special health care facilities or the number of hospital days during the first 5 years of life.

Compared with the controls, the VLBWI had significantly higher scores in all FTF domains indicating more developmental and behavioural problems (Table 2). According to Finnish normative values for the FTF, 8.3\% of the study VLBWI had considerable difficulties in the domain of motor skills, $7.8 \%$ in executive functions, $3.9 \%$ in perception, $8.4 \%$ in memory, $4.6 \%$ in language, $4.3 \%$ in social skills and $3.4 \%$ in emotional and behavioural problems. On the other hand, the percentages of those VLBWI within the normal range were 66, 68, 56, 59, 68, 67 and $65 \%$, respectively. In our controls, $2.8 \%$ had considerable problems in the domain of memory and
$2.8 \%$ in language but only $0.6 \%$ in motor skills and none in the rest of the domains. In the controls, the percentages of children in the normal range were $86 \%$ in the domain of motor skills, $83 \%$ in executive functions, $70 \%$ in perception, $61 \%$ in memory, $82 \%$ in language, $68 \%$ in social skills and $77 \%$ in emotional and behavioural problems.

The FTF domain scores were less optimal with decreasing GA (Fig. 1). In VLBWI, the scores of all eight main domains significantly decreased with increasing GA. An increase of 1 week in GA was associated with a 0.9 -fold lower score in all main domains, i.e. motor skills $(p<0.0001)$, executive functions $(p=0.0096)$, perception $(p<0.0001)$, memory $(p=0.0007)$, language $(p=0.0002)$, learning $\quad(p=$ $0.0002)$, social skills $(p=0.0007)$ and emotional and behavioural problems ( $p=0.0029)$.

There were no significant differences in the behavioural and developmental domain scores between VLBWI compared according to the birth hospital level (Table 3), the university hospital district (Table 4) and the time of birth (Table 5). 
Table 2 Developmental and behavioural scores from the Five to Fifteen questionnaire (FTF) in VLBWI and controls

\begin{tabular}{|c|c|c|c|c|}
\hline FTF domain & VLBWI (unadjusted mean) & Controls (unadjusted mean) & Adjusted RR & $95 \% \mathrm{CI}$ \\
\hline Motor skills & 0.38 & 0.18 & 2.22 & $1.83-2.69$ \\
\hline Gross motor skills & 0.36 & 0.13 & 2.89 & $2.16-3.86$ \\
\hline Fine motor skills & 0.40 & 0.22 & 1.91 & $1.59-2.30$ \\
\hline Executive functions & 0.42 & 0.26 & 1.53 & $1.29-1.82$ \\
\hline Attention & 0.44 & 0.23 & 1.81 & $1.47-2.23$ \\
\hline Hyperactive/impulsive & 0.47 & 0.35 & 1.28 & $1.07-1.53$ \\
\hline Hypoactive & 0.26 & 0.10 & 2.63 & $1.88-3.66$ \\
\hline Planning/organising & 0.40 & 0.30 & 1.34 & $1.07-1.68$ \\
\hline Perception & 0.24 & 0.13 & 1.92 & $1.55-2.39$ \\
\hline Relation in space & 0.24 & 0.11 & 2.27 & $1.68-3.06$ \\
\hline Body perception & 0.22 & 0.13 & 1.76 & $1.34-2.33$ \\
\hline Visual perception & 0.26 & 0.15 & 1.83 & $1.38-2.43$ \\
\hline Memory & 0.32 & 0.26 & 1.26 & $1.01-1.58$ \\
\hline Language & 0.30 & 0.18 & 1.64 & $1.33-2.01$ \\
\hline Comprehension & 0.30 & 0.18 & 1.61 & $1.25-2.07$ \\
\hline Expressive language skills & 0.29 & 0.18 & 1.65 & $1.31-2.07$ \\
\hline Communication & 0.31 & 0.17 & 1.76 & $1.30-2.38$ \\
\hline Learning & 0.39 & 0.22 & 1.67 & $1.35-2.06$ \\
\hline Coping in learning & 0.41 & 0.25 & 1.60 & $1.30-1.98$ \\
\hline General learning & 0.31 & 0.16 & 1.91 & $1.42-2.56$ \\
\hline Social skills & 0.21 & 0.11 & 1.83 & $1.44-2.34$ \\
\hline Emotional/behavioural problems & 0.16 & 0.11 & 1.49 & $1.20-1.84$ \\
\hline Internalising & 0.13 & 0.08 & 1.56 & $1.19-2.05$ \\
\hline Externalising & 0.23 & 0.17 & 1.39 & $1.09-1.78$ \\
\hline Obsessive compulsive & 0.10 & 0.05 & 1.79 & $1.22-2.62$ \\
\hline
\end{tabular}

The rate ratio (RR) estimates describe how many times higher scores do VLBWI have in comparison to the controls after adjustments for sex, family structure and the mother's and the father's years of education and employment status

Fig. 1 The developmental and behavioural scores according to the parental Five to Fifteen questionnaire. The main domain score means are presented according to GA groups in the VLBWI and separately for the full-term controls. The scale ranges from 0 (no problems) to 2

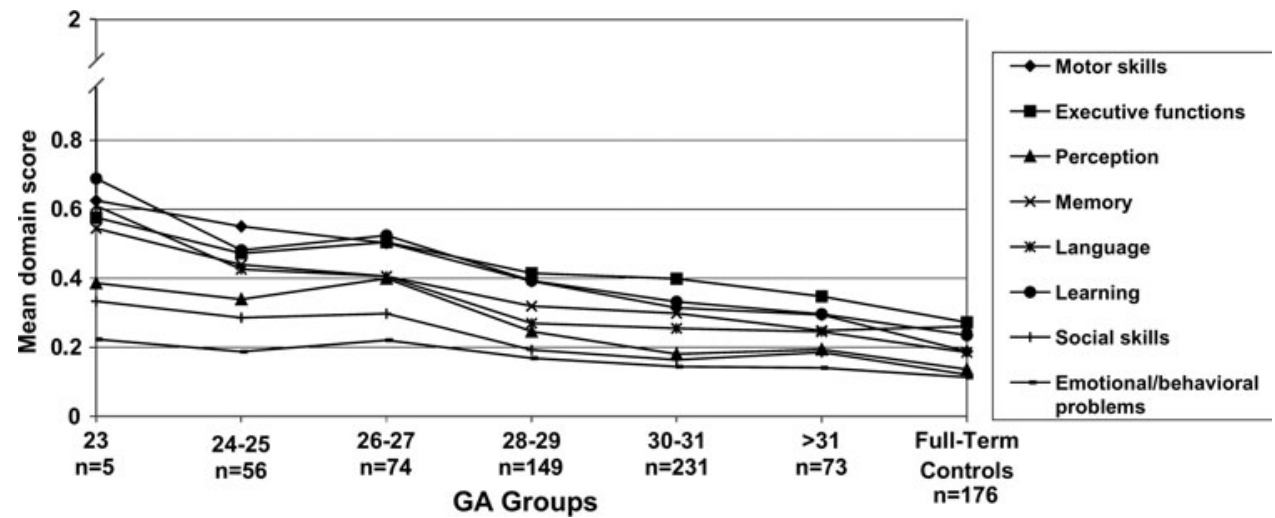

the birth hospital level, or the university hospital district of birth.

We linked the questionnaires to the Finnish National Birth Register data that have been shown to be reliable [24]. The extensive background information enabled us to adjust for several important background variables. This was necessary as patient selection between level II and III hospitals naturally differed. In addition, we were able to 
Table 3 Developmental and behavioural scores of VLBWI born in level II and III hospitals according to the Five to Fifteen questionnaire (FTF)

\begin{tabular}{|c|c|c|c|c|}
\hline FTF domain & Level II (unadjusted mean) & Level III (unadjusted mean) & Adjusted RR & $95 \% \mathrm{CI}$ \\
\hline Motor skills & 0.34 & 0.39 & 1.04 & $0.83-1.30$ \\
\hline Executive functions & 0.42 & 0.42 & 1.13 & $0.91-1.39$ \\
\hline Perception & 0.23 & 0.25 & 1.22 & $0.94-1.57$ \\
\hline Memory & 0.28 & 0.33 & 1.04 & $0.78-1.37$ \\
\hline Language & 0.26 & 0.30 & 1.04 & $0.82-1.34$ \\
\hline Learning & 0.34 & 0.39 & 1.03 & $0.79-1.33$ \\
\hline Social skills & 0.18 & 0.21 & 0.93 & $0.69-1.26$ \\
\hline Emotional/behavioural problems & 0.15 & 0.17 & 0.92 & $0.71-1.21$ \\
\hline
\end{tabular}

The rate ratio (RR) estimates of birth in level III hospital are adjusted for intrauterine growth, multiple births, sex, gestational age, birthweight, non-lethal malformations, the mother's and the father's years of education and employment status, and family structure

Table 4 Developmental and behavioural scores of VLBWI born in five different hospital districts according to the Five to Fifteen questionnaire (FTF)

\begin{tabular}{|c|c|c|c|c|c|c|}
\hline FTF domain & $\begin{array}{l}\text { District A } \\
\text { (unadjusted mean) }\end{array}$ & $\begin{array}{l}\text { District B } \\
\text { (unadjusted mean) }\end{array}$ & $\begin{array}{l}\text { District C } \\
\text { (unadjusted mean) }\end{array}$ & $\begin{array}{l}\text { District D } \\
\text { (unadjusted mean) }\end{array}$ & $\begin{array}{l}\text { District E } \\
\text { (unadjusted mean) }\end{array}$ & $\begin{array}{l}\text { Adjusted } p \\
\text { value }\end{array}$ \\
\hline Motor skills & 0.38 & 0.40 & 0.35 & 0.41 & 0.38 & 0.84 \\
\hline Executive functions & 0.40 & 0.42 & 0.42 & 0.44 & 0.43 & 0.87 \\
\hline Perception & 0.24 & 0.25 & 0.22 & 0.26 & 0.25 & 0.62 \\
\hline Memory & 0.31 & 0.37 & 0.25 & 0.32 & 0.38 & 0.06 \\
\hline Language & 0.27 & 0.30 & 0.28 & 0.31 & 0.34 & 0.44 \\
\hline Learning & 0.36 & 0.42 & 0.34 & 0.41 & 0.41 & 0.54 \\
\hline Social skills & 0.20 & 0.19 & 0.19 & 0.22 & 0.23 & 0.98 \\
\hline $\begin{array}{l}\text { Emotional/ } \\
\text { behavioural } \\
\text { problems }\end{array}$ & 0.16 & 0.16 & 0.16 & 0.17 & 0.18 & 0.97 \\
\hline
\end{tabular}

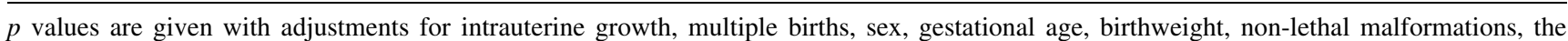
mother's and the father's years of education and employment status, and family structure

Table 5 Developmental and behavioural scores of VLBWI from the Five to Fifteen questionnaire (FTF) according to time of birth

\begin{tabular}{|c|c|c|c|c|}
\hline FTF domain & Outside office hours (unadjusted mean) & Office hours (unadjusted mean) & Adjusted RR & $95 \% \mathrm{CI}$ \\
\hline Motor skills & 0.38 & 0.38 & 0.88 & $0.74-1.05$ \\
\hline Executive functions & 0.43 & 0.40 & 1.05 & $0.89-1.24$ \\
\hline Perception & 0.25 & 0.23 & 0.97 & $0.79-1.18$ \\
\hline Memory & 0.34 & 0.29 & 1.15 & $0.93-1.44$ \\
\hline Language & 0.30 & 0.28 & 1.02 & $0.84-1.24$ \\
\hline Learning & 0.40 & 0.35 & 1.10 & $0.90-1.34$ \\
\hline Social skills & 0.21 & 0.19 & 1.08 & $0.85-1.37$ \\
\hline Emotional/behavioural problems & 0.16 & 0.17 & 0.88 & $0.71-1.09$ \\
\hline
\end{tabular}

The rate ratio (RR) estimates for birth outside office hours are adjusted for intrauterine growth, multiple births, sex, gestational age, birthweight, non-lethal malformations, the mother's and the father's years of education and employment status, and family structure

perform a detailed drop-out analysis ruling out attrition bias concerning child health. The drop-out analysis is necessary in follow-up studies of VLBWI since the incidence of adverse outcomes have been shown to be underestimated when follow-up is incomplete, and boys, non-natives and those with low maternal education have participated less often $[25,26]$. In our study, parents of the boys responded more often than the parents of the girls. More importantly, the responders did not differ from the non-responders in birthweight, GA, or the frequency of use of special health care services. This indicates that there was no drop-out bias favouring healthier children. Therefore, it is unlikely that developmental or behavioural problems were under- or overestimated in our study. Since the 
mothers of full-term infants have been less willing to participate in trials than mothers of preterm infants [27], we had, as expected, a lower response rate for the controls than for the VLBWI. The parents of VLBWI are more likely to regard this type of study as important than the parents of the controls.

The FTF has been shown to be a sensitive instrument suitable for screening of developmental and behavioural problems [19-22]. The sensitivity of the FTF in 5-yearold children from the general population was $93 \%$, although the specificity was only $63 \%$ when it was compared to the NEPSY neuropsychological assessment instrument [21]. In VLBWI, the neuropsychological performance assessed by a psychologist with NEPSY II domains on executive functioning, language and motor skills have been shown to significantly associate with the corresponding FTF domains [28]. When using the FTF, the children are evaluated by proxy, not by using clinical tests. Therefore, it is not possible to assess the influence of the parents' subjective opinion on the results, and this may lower the diagnostic accuracy. In this study, however, the FTF detected differences between VLBWI and healthy controls, as well as gestational and age-related differences in VLBWI.

Our findings clearly parallel earlier results about increased difficulties related to the development and behaviour in preterm infants at 5 years of age $[10,13]$ and in school age [14, 29] when compared with controls. In agreement with our results, parents have also reported VLBWI to have more social problems in adolescence [30] and attention problems in adolescence [30] and young adulthood [31] than controls. Parallel to our results, increased problems in learning, language and perception in VLBWI compared to full-term controls have also been found in 7-14-year-old children born with an extremely low birthweight $(<750 \mathrm{~g})$ [32]. These problems may lead to an increased need for support at school. Poorer academic readiness and achievement [33-35] and need for special education $[36,37]$ have been reported in preterm children.

In addition to the association between high hospital level and decreased mortality of VLBWI [4-6], high patient volumes have been associated with decreased mortality $[4,38]$ and rate of severe intraventricular haemorrhages (IVH) in VLBWI [39]. As shown in our previous study [5], VLBWI born in level III hospitals had lower 1-year mortality rates than those born in level II hospitals. Despite these findings, no differences were found in parental assessments on behavioural or developmental problems in the surviving VLBWI at 5 years of age between level II and level III hospitals or according to the time of birth in the current study. We could not, however, separately analyse the effect of patient volume and hospital level since all
Finnish hospitals with a large VLBWI patient volume are level III university hospitals, whereas level II hospitals have relatively small VLBWI patient volumes.

Being born outside office hours was not associated with the outcome of VLBWI in Finland at 5 years of age, suggesting that possible differences in the quality of initial care according to the time of birth $[5,7]$ are no longer reflected on the outcome at 5 years of age. Similarly, we found no differences according to the time of birth in the health-related quality of life at age 5 or quality adjusted life-years of VLBWI [16]. Parallel to our results, an Australian study found no association between the time of birth and severe IVH, PDA, NEC, BPD, or grade 3 or 4 retinopathy of prematurity [40]. However, they included only infants born in level III hospitals, which are likely to have larger allocation of resources to care outside office hours than the Finnish level II hospitals do.

Regional differences have previously been shown in Finland in the morbidity of VLBWI born in 1996-1997 [9]. In our own data, the initial length of hospital stay varied between the five university hospital districts [8]. In this study, it was encouraging to notice that regional differences were not seen in the behaviour and development at 5 years of age.

\section{Conclusion}

Optimal organisation of the care of VLBWI should be defined according to analyses of long-term outcomes for these children. Our study showed that the FTF differentiates behavioural and developmental problems between VLBWI and controls at 5 years of age. No differences in behaviour or development were seen in VLBWI between the birth hospital levels, university hospital districts, or time of birth, despite the differences previously shown in mortality. Our results suggest that mortality is a good indicator of the quality of initial care of VLBWI in Finland. Based on parental questionnaire data, we conclude that in hospitals with increased survival, the survival advantage seems not to be gained at the expense of to developmental problems.

Acknowledgments Members of the Performance, Effectiveness, and Cost of Treatment Episodes (PERFECT) Preterm Infant Study Group include all authors, Miika Linna, and Mikko Peltola. This study was supported by the Finnish Academy (Research Program on Health Services Research), the South-West Finnish Fund of Neonatal Research, the University Hospital EVO Funds, and the Turku University Hospital Foundation. Special thanks to Dr. Marit Korkman for her advice on the use of the Five to Fifteen questionnaire.

Conflict of interest statement All authors declare that they have no conflicts of interests relevant to this article to disclose. 


\section{References}

1. Field DJ, Dorling JS, Manktelow BN, Draper ES (2008) Survival of extremely premature babies in a geographically defined population: prospective cohort study of 1994-9 compared with 2000-5. BMJ 336:1221-1223

2. Fanaroff AA, Stoll BJ, Wright LL, Carlo WA, Ehrenkranz RA, Stark AR, Bauer CR, Donovan EF, Korones SB, Laptook AR, Lemons JA, Oh W, papile LA, Shankaran S, Stevenson DK, Tyson JE, Poole WK, NICHD Neonatal Research Network (2007) Trends in neonatal morbidity and mortality for very low birthweight infants. Am J Obstet Gynecol 196:147.e1-147.e8

3. Palta M, Sadek-Badawi M, Evans M, Weinstein MR, McGuinnes G (2000) Functional assessment of a multicenter very low-birthweight cohort at age 5 years. Newborn Lung Project. Arch Pediatr Adolesc Med 154:23-30

4. Phibbs CS, Baker LC, Caughey AB, Danielsen B, Schmitt SK, Phibbs RH (2007) Level and volume of neonatal intensive care and mortality in very-low-birth-weight infants. N Engl J Med 356:2165-2175

5. Rautava L, Lehtonen L, Peltola M, Korvenranta E, Korvenranta H, Linna M, Hallman M, Andersson S, Gissler M, Leipälä J, Tammela O, Häkkinen U, Preterm Infant Study Group PERFECT (2007) The effect of birth in secondary- or tertiary-level hospitals in Finland on mortality in very preterm infants: a birth-register study. Pediatrics 119:e257-e263

6. Johansson S, Montgomery SM, Ekbom A, Olausson PO, Granath F, Norman M, Cnattingius S (2004) Preterm delivery, level of care, and infant death in Sweden: a population-based study. Pediatrics 113:1230-1235

7. Gould JB, Qin C, Chavez G (2005) Time of birth and the risk of neonatal death. Obstet Gynecol 106:352-358

8. Korvenranta E, Linna M, Hakkinen U, Peltola M, Andersson S, Gissler M, Hallman M, Korvenranta H, Leipälä J, Rautava L, Tammela O, Lehtonen L, PERFECT Preterm Infant Study Group (2007) Differences in the length of initial hospital stay in very preterm infants. Acta Paediatr 96:1416-1420

9. Tommiska V, Heinonen K, Lehtonen L, Renlund M, Saarela T, Tammela O, Virtanen M, Fellman V (2007) No improvement in outcome of nationwide extremely low birth weight infant populations between 1996-1997 and 1999-2000. Pediatrics 119:29-36

10. van Baar AL, van Wassenaer AG, Briet JM, Dekker FW, Kok JH (2005) Very preterm birth is associated with disabilities in multiple developmental domains. J Pediatr Psychol 30:247-255

11. Larroque B, Ancel PY, Marret S, Marchand L, Andre M, Arnaud C, Pierrat V, Roze JC, Messer J, Thiriez G, Burguet A, Picaud JC, Breart G, Kaminski M, EPIPAGE Study Group (2008) Neurodevelopmental disabilities and special care of 5-year-old children born before 33 weeks of gestation (the EPIPAGE study): a longitudinal cohort study. Lancet 371:813-820

12. Mikkola K, Ritari N, Tommiska V, Salokorpi T, Lehtonen L, Tammela O, Pääkkönen L, Olsen P, Korkman M, Fellman V (2005) Neurodevelopmental outcome at 5 years of age of a national cohort of extremely low birth weight infants who were born in 1996-1997. Pediatrics 116:1391-1400

13. Hoff B, Hansen BM, Munck H, Mortensen EL (2004) Behavioral and social development of children born extremely premature: 5-year follow-up. Scand J Psychol 45:285-292

14. Bhutta AT, Cleves MA, Casey PH, Cradock MM, Anand KJ (2002) Cognitive and behavioral outcomes of school-aged children who were born preterm: a meta-analysis. JAMA 288:728737

15. Darlow BA, Horwood LJ, Mogridge N (2000) Regional differences in outcome for very low-birthweight infants: do they persist at 7-8 years of age? J Paediatr Child Health 36:477-481
16. Rautava L, Häkkinen U, Korvenranta E, Andersson S, Gissler M, Hallman M, Korvenranta H, Leipälä J, Linna M, Peltola M, Tammela O, Lehtonen L (2009) Health-related quality of life in 5-year-old very low birth weight infants. J Pediatr 155:338-343

17. Rautava L, Häkkinen U, Korvenranta E, Andersson S, Gissler M, Hallman M, Korvenranta H, Leipälä J, Peltola M, Tammela O, Lehtonen L, PERFECT Preterm Infant Study Group (2010) Health and the use of health care services in five-year-old verylow-birth-weight infants. Acta Paediatr (in press)

18. Stark AR, American Academy of Pediatrics Committee on Fetus and Newborn (2004) Levels of neonatal care. Pediatrics 114:1341-1347

19. Bohlin G, Janols LO (2004) Behavioural problems and psychiatric symptoms in 5-13 year-old Swedish children-a comparison of parent ratings on the FTF (Five to Fifteen) with the ratings on CBCL (Child Behavior Checklist). Eur Child Adolesc Psychiatry 13(Suppl 3):14-22

20. Kadesjö B, Janols LO, Korkman M, Mickelsson K, Strand G, Trillingsgaard A, Gillberg C (2004) The FTF (Five to Fifteen): the development of a parent questionnaire for the assessment of ADHD and comorbid conditions. Eur Child Adolesc Psychiatry 13(Suppl 3):3-13

21. Korkman M, Jaakkola M, Ahlroth A, Pesonen AE, Turunen MM (2004) Screening of developmental disorders in five-year-olds using the FTF (Five to Fifteen) questionnaire: a validation study. Eur Child Adolesc Psychiatry 13(Suppl 3):31-38

22. Trillingsgaard A, Damm D, Sommer S, Jepsen JR, Ostergaard O, Frydenberg M, Thomsen PH (2004) Developmental profiles on the basis of the FTF (Five to Fifteen) questionnaire-clinical validity and utility of the FTF in a child psychiatric sample. Eur Child Adolesc Psychiatry 13(Suppl 3):39-63

23. Korkman M, Kadesjö B, Trillingsgaard A, Janols L, Michelsson K, Strand G, Gillberg C (2005) VIIVI-käsikirja [FTF manual in Finnish], 1st edn. ADHD-liitto ry, Helsinki

24. Gissler M, Teperi J, Hemminki E, Merilainen J (1995) Data quality after restructuring a national medical registry. Scand J Soc Med 23:75-80

25. Hille ET, Elbertse L, Gravenhorst JB, Brand R, Verloove-Vanhorick SP, Dutch POPS-19 Collaborative Study Group (2005) Nonresponse bias in a follow-up study of 19-year-old adolescents born as preterm infants. Pediatrics 116:e662-e666

26. Hille ET, den Ouden AL, Stuifbergen MC, Verrips GH, Vogels AG, Brand R, Verloove-Vanhorick SP, Dutch POPS-19 Collaborative Study Group (2005) Is attrition bias a problem in neonatal follow-up? Early Hum Dev 81:901-908

27. Maayan-Metzger A, Kedem-Friedrich P, Kuint J (2008) Motivations of mothers to enroll their newborn infants in general clinical research on well-infant care and development. Pediatrics 121:e590-e596

28. Lind A, Haataja L, Rautava L, Väliaho A, Lehtonen L, Lapinleimu H, Parkkola R, Korkman M, PIPARI Study Group (2009) Relations between brain volumes, neuropsychological assessment and parental questionnaire in prematurely born children. Eur Child Adolesc Psychiatry. doi:10.1007/s00787-009-0070-3

29. Anderson P, Doyle LW, Victorian Infant Collaborative Study Group (2003) Neurobehavioral outcomes of school-age children born extremely low birth weight or very preterm in the 1990s. JAMA 289:3264-3272

30. Dahl LB, Kaaresen PI, Tunby J, Handegard BH, Kvernmo S, Ronning JA (2006) Emotional, behavioral, social, and academic outcomes in adolescents born with very low birth weight. Pediatrics 118:e449-e459

31. Hack M, Youngstrom EA, Cartar L, Schluchter M, Taylor HG, Flannery D, Klein N, Borawski E (2004) Behavioral outcomes and evidence of psychopathology among very low birth weight infants at age 20 years. Pediatrics 114:932-940 
32. Taylor HG, Minich NM, Klein N, Hack M (2004) Longitudinal outcomes of very low birth weight: neuropsychological findings. J Int Neuropsychol Soc 10:149-163

33. Finnström O, Gäddlin PO, Leijon I, Samuelsson S, Wadsby M (2003) Very-low-birth-weight children at school age: academic achievement, behavior and self-esteem and relation to risk factors. J Matern Fetal Neonatal Med 14:75-84

34. Hagen EW, Palta M, Albanese A, Sadek-Badawi M (2006) School achievement in a regional cohort of children born very low birthweight. J Dev Behav Pediatr 27:112-120

35. Weindrich D, Jennen-Steinmetz C, Laucht M, Schmidt MH (2003) Late sequelae of low birthweight: mediators of poor school performance at 11 years. Dev Med Child Neurol 45:463469

36. Wocadlo C, Rieger I (2006) Educational and therapeutic resource dependency at early school-age in children who were born very preterm. Early Hum Dev 82:29-37
37. Saigal S, den Ouden L, Wolke D, Hoult L, Paneth N, Streiner DL, Whitaker A, Pinto-Martin J (2003) School-age outcomes in children who were extremely low birth weight from four international population-based cohorts. Pediatrics 112:943-950

38. Rogowski JA, Horbar JD, Staiger DO, Kenny M, Carpenter J, Geppert J (2004) Indirect vs direct hospital quality indicators for very low-birth-weight infants. JAMA 291:202-209

39. Synnes AR, Macnab YC, Qiu Z, Ohlsson A, Gustafson P, Dean CB, Lee SK, Canadian Neonatal Network (2006) Neonatal intensive care unit characteristics affect the incidence of severe intraventricular hemorrhage. Med Care 44:754-759

40. Abdel-Latif ME, Bajuk B, Oei J, Lui K, New South Wales and the Australian Capital Territory Neonatal Intensive Care Audit Group (2006) Mortality and morbidities among very premature infants admitted after hours in an Australian neonatal intensive care unit network. Pediatrics 117:1632-1639 